\title{
Espaços da violência na narrativa brasileira contemporânea
}

\author{
Valdemar Valente Junior ${ }^{1}$
}

O sucesso alcançado por Cidade de Deus, de Paulo Lins (2002), situa-se como ponto de partida no processo de afirmação em que se torna evidente a presença da produção narrativa da periferia urbana como fenômeno inevitável. A isso podem ser acrescidos valores referentes ao discurso dos que vivem nas ruas das grandes cidades bem como dos que cumprem pena em prisões e do submundo retiram forças para narrar o que representa a crueldade de um universo de desigualdade e violência. O livro de Paulo Lins tem importância decisiva no fato de que, além da recepção favorável por parte da crítica, ${ }^{2}$ constituiu-se em fenômeno de venda, haja vista a aceitação que lhe abriu a possibilidade de traduções no exterior, além do fenômeno inquestionável de sua adaptação para o cinema, tendo sido, ainda, apresentado como seriado da televisão.

Por tudo isso o feito de Cidade de Deus insere-se numa ordem de reconhecimento que não tem como recuar diante dos espaços que lhe foram franqueados. Não se trata mais da situação de retorno a uma condição inicial, a exemplo do êxito de Quarto de despejo, ${ }^{3}$ de Carolina Maria de Jesus (1960), que em sua inabilidade não teve condições de lidar com a fama repentina que lhe caiu no colo. Os tempos são outros e a luta por pertencimento acaba por agregar de forma positiva os escritores oriundos das camadas periféricas e excluídas. Por sua vez, o mercado não joga o jogo dos perdedores, sendo esses novos autores, pela própria condição que os situa na escrita como na vida, capazes de mudar o resultado da partida. Além disso, a possibilidade de inserção efetiva-se nas próprias frestas do sistema que tanto os rejeita quanto os acolhe. Esses artistas buscam na escrita uma legitimação para a qual concorre a denúncia como espaço de hiper-realidade.

Ao desvelar esse filão do mercado editorial, Cidade de Deus abre amplas possibilidades ao florescimento do que frutificaria como crescente espaço

\footnotetext{
${ }^{1}$ Doutor em ciência da literatura e professor de literatura brasileira da Universidade Castelo Branco e da UniverCidade, Rio de Janeiro, RJ, Brasil. E-mail: valdemarvalente@gmail.com

${ }^{2}$ No ensaio intitulado "Cidade de Deus", Roberto Schwarz (1999) destaca o que o escritor caracteriza como "neofavela", que contraria o conceito tradicional de favela, sendo, portanto, o espaço dominado pela ação armada do narcotráfico, além da violência e da corrupção exercidas pela polícia.

3 O sucesso dessa obra traduzida em diversos países, além de situar-se como uma referência da identidade brasileira, deveu-se em grande medida à euforia vivida no país pela urgência de mudanças no âmbito social que antecedeu o golpe militar de 1964.
} 
de discussão envolvendo o lugar da literatura no plano da cultura de massas. Além disso, a imbricação que traz à cena o livro, o filme e o seriado da televisão é como uma continuidade de valor altamente positivo no que se refere à abertura de espaços à fixação de uma nova realidade que se estende à produção da última década. Os conflitos decorrentes da crise permanente que assola os centros urbanos, com ênfase para o Rio de Janeiro e São Paulo, tendo em vista nossa condição de país em processo abrupto de transformação, são como um mapa a ser investigado. No entanto, o roteiro da desigualdade e da violência concorre para que se configure um hiato separando os efetivamente excluídos dos espaços de consumo restritos às camadas superiores a partir de um quadro definido de estratificação.

Por esse meio, a primeira década do milênio contribui para que de fato se efetivasse a possibilidade de a narrativa estreitar relações extremas com a realidade de quem a escreve. Não se trata mais da descrição dos dramas sociais a partir do filtro cultural devidamente incorporado ao status quo do escritor que se debruça sobre a causa dos excluídos. Dessa vez, os autores protagonizam sua tragédia, configurando o ambiente da exclusão e do desrespeito humano como matéria-prima de narrativas quase sempre marcadas pela aspereza da linguagem que lhe dá origem. No entanto, o que pode se constituir em desregramento se confirma como condição inovadora na medida do que se coaduna à realidade in loco do submundo de onde é retirada. Situado em zonas de extremo conflito, o conjunto dessas narrativas possibilita a apreensão da crise do capitalismo em sua agudeza, constituindo-se em valioso material de análise e observação da situação brasileira na atualidade.

Assim, buscaremos subsídios que confirmem essas propostas nos textos de Ferréz, Luiz Alberto Mendes e Alessandro Buzo. Capão Pecado, Memórias de um sobrevivente e Guerreira promovem o inventário do tráfico de drogas, da prostituição e do latrocínio no cenário de um teatro de violências que radicaliza o processo extremamente contraditório das transformações que se conflitam no país como um de seus mais graves dilemas. O processo de legitimação das manifestações da cultura subalterna passa então a um plano de exposição que lhe confere um lugar de referência na produção cultural do que se confirma pela exclusão. Por conta das temáticas que suscitam, as narrativas em questão possuem a capacidade orgânica de assumir um espaço de importância na indústria cultural sem que isso represente nenhuma forma de alienação. A negociação com a cultura de massas não interfere na abordagem dos problemas evidenciados, mas lhes dá a dimensão da catástrofe que foge por completo ao folclore da miséria e da injustiça. 
A criminalidade como marco divisório, num mundo sem coração, onde a solidariedade cede espaços ao aperfeiçoamento de um sistema que retira seu lucro da atividade ilícita, é a regra que se impõe ao crime a partir de uma lógica de mercado. Por isso, atividades como o narcotráfico e a prostituição são incorporadas a um modelo de exploração de contorno profissional, não havendo lugar para nenhum tipo de relação pessoal que envolva um desvio no plano dos resultados auferidos. O crime profissionaliza-se com o requinte que exige o crescente aperfeiçoamento da máquina capitalista. A produção textual nascida das contradições decorrentes do crime organizado, no universo das favelas, ruas e presídios, envolvendo marginais, prostitutas, policiais, etc., assume uma importância que a qualifica como estilo, incorporando-a ao sentido de denúncia que se valoriza em vista das configurações inovadoras inseridas nessas narrativas.

O mérito intrínseco dos textos não se deve apenas ao que estes possam representar por conta de um possível aspecto pitoresco dos excluídos que agora assumem um lugar do discurso, senão pela importância natural dessas obras inseridas na realidade de seu próprio tempo, suscitando questionamentos e sugerindo, a partir da própria atitude desses escritores, formas de enfrentamento e superação da desigualdade abissal que os separa de um plano de expectativa com relação às classes superiores. Assim, a exposição dessas obras ao crivo de um mercado tradicionalmente atrelado ao gosto das elites cultas concorre para que a subversão dessa ordem busque inserir as vozes dos que não têm vez. A narrativa visceral de Ferréz, Luiz Alberto Mendes e Alessandro Buzo, assim como a de tantos outros que têm conseguido romper a barreira do silêncio e do isolamento cultural, significa que mais do que nunca podemos superar posições de classe e formação para formular outro conceito de escrita de vital importância ao entendimento do tempo em que vivemos.

\section{Nos confins da periferia}

Os elementos da narrativa ambientada na periferia dos centros urbanos têm ganhado a cada dia novos espaços na mídia, tornando-se uma realidade irrefutável. A isso não corresponde nenhuma benesse do sistema, muito pelo contrário, representa o resultado de conquistas que no decorrer do tempo têm efetivado sua marca. Se no passado o lugar do subalterno significava uma concessão correspondente ao beija-mão, numa espécie de visto provisório, hoje esse espaço se legitima no universo das mercadorias oferecidas no plano da indústria cultural. A abertura propiciada pela massificação da oferta de bens culturais não pode prescindir das diferentes formas de expressão da escrita da periferia que pedem 
passagem impondo sua presença. Os escritores dessas áreas de conflito marcadas pelo estigma da violência são a tônica de um momento em que se faz preciso ter a devida atenção sobre esses espaços e refletir sobre o que nos apresenta a visão dos que escrevem com conhecimento de causa, de dentro do foco da violência.

Para estes a escrita funciona como um canal de acesso aos meios midiáticos incorporando a linguagem rápida do hip-hop, dos grafites, dos quadrinhos, e reduzindo a zero os limites da oralidade como barreira entre classes. Sobre esse aspecto específico, os textos de Ferréz pontificam como elemento expressivo. Tratando dos elevados níveis de desigualdade comuns aos bairros da periferia de São Paulo, sua escrita configura a invasão de um nicho cultural dominado pelos modelos de um bom gosto que atende às expectativas do pensamento hegemônico. Esse mercado, no entanto, não tem como não conter a força dessa escrita desviante e acaba incorporando-a a uma multiplicidade de bens que se apresentam no bazar das surpresas culturais seguidamente oferecidas. Em vista disso, Capão Pecado situa-se como escrita da diferença, ajudando a engrossar o coro dos descontentes na maior cidade do país. O texto de Ferréz (2005) tem urgência em evidenciar o descompasso social que atinge a periferia paulistana:

Essa tendência neodocumental da ficção, com tinturas tardo-naturalistas, constitui a referência óbvia à compulsão pelas situações-limite na vida social. Desde o aparecimento do Cidade de Deus, de Paulo Lins, sucedido por muitas outras narrativas da marginalidade e da exclusão - como o Estação Carandiru de Drauzio Varella, o Memórias de um sobrevivente de Luiz Alberto Mendes, ou ainda o Capão pecado de Ferréz - que o esforço testemunhal dos narradores, diante da desumana inserção social vivenciada, patenteia-se na linguagem fluida, comunicável, de forte compleição jornalística, na obsessão etnográfica com a contextualização da cena e dos caracteres, bem como na enfática objetivação da violência, em precisos recortes de extremos da torpeza humana (Dias, 2005, p. 87-88).

A dinâmica da linguagem que se impõe configura a adversidade da qual essa população é diariamente obrigada a se desviar, evitando o risco de um choque de consequências fatais. A indigência social, o desemprego, o narcotráfico e a ação da polícia são situações comuns a que se agrega um código verbal inovador. O escritor da periferia não tem como evitar algo que lhe é essencial no âmbito da linguagem. Assim, Capão Pecado ratifica a visão de Ferréz sobre um território sem remissão, onde habita uma juventude sem horizontes que não sejam os de reiteração dos códigos da linguagem como canal de expressão. Além disso, lhe cabe como tábua de 
salvação provisória tentar ocupar postos no âmbito da prestação de serviços subalternos para sobreviver ao crime e à violência.

A narrativa de Ferréz mantém um elevado nível de comprometimento com o que lhe é original, não desprezando nada do que a integra como seu maior valor. Ao aliar-se ao meio como uma forma de afirmação de sua gênese, reitera um lugar de pertencimento que concorre decisivamente como moeda para sua aceitação no mercado. A diversidade de tons do discurso, no texto, que corresponde a uma abertura cada vez maior de sua recepção, tem um efeito significativo a partir do momento em que o Capão Redondo passa a integrar-se ao mapa dos acontecimentos que vão além das notícias sobre a marginalidade e o tráfico de drogas. $O$ fato de que o texto de Ferréz em si já significa a possibilidade de reconfiguração desse espaço, ainda que reitere o lugar da conhecida violência, serve de algum modo para desviar um foco específico de atenção sobre o que se confirma num lugar comum, reinventando a crise nas formas possíveis de expressão da linguagem periférica.

A certa altura, o texto parte para um plano de caracterização do papel da televisão como veículo de alienação das massas, o que incide na acusação da manipulação que esta exerce como desvirtuação que se projeta sobre os pobres a partir dos sonhos que divulga. Contra isso, o rap tem o poder de ser um código de manutenção do foco de resistência contra o conformismo alienante. Em Capão Pecado os espaços da exclusão são submetidos ao inventário de quem conhece a realidade de perto, olhando de dentro o problema como este se apresenta. Os males que atingem o Capão Redondo situam-se no texto como consequência de natureza macrossocial, o que parece ter a proporção do que ocorre em São Paulo em sua configuração mais ampla. A discussão sobre um determinado dado de realidade recai numa espécie de realismo em si mesmo, a partir da ampliação da possibilidade do discurso para além do literário:

Não se trata, portanto, de um realismo tradicional e ingênuo em busca da ilusão de realidade. Nem se trata, tampouco, de um realismo propriamente representativo; a diferença que mais salta aos olhos é que os "novos realistas" querem provocar efeitos de realidade por outros meios. Ora, discutindo um realismo que não se pretende mimético nem propriamente representativo, o problema ameaça tornar-se um paradoxo, uma vez que o compromisso representativo da literatura historicamente surge com a aparição do fenômeno realista. De que realismo falamos então, se não o representativo? Diríamos, inicialmente, que o novo realismo se expressa pela vontade de relacionar a literatura e a arte com a realidade social e cultural da qual emerge, incorporando essa realidade esteticamente dentro da obra e situando a própria produção artística como força transformadora. 
Estamos falando de um tipo de realismo que conjuga as ambições de ser "referencial", sem necessariamente ser representativo, e ser, simultaneamente, "engajado", sem necessariamente subscrever nenhum programa político ou pretender transmitir de forma coercitiva conteúdos ideológicos prévios (Schøllhammer, 2009, p. 53-4).

Assim, não há outro meio de legitimação do lugar do subalterno numa sociedade de classes que não transite pelos códigos da escrita. Os rappers, grafiteiros e escritores marginais são um caminho viável à superação da própria condição que lhes oferece o meio. Com relação às drogas, Capão Pecado assume uma posição de alerta quanto à autoestima aviltada por seu consumo. A devastação decorrente das drogas concorre para que o submundo do Capão Redondo tenha como registro um elevado elenco de traumas herdados das formas mais desumanas do que o capitalismo pode gerar. No Capão Redondo as coisas já são ruínas antes mesmo de ser confirmada sua funcionalidade. As ruas tornam-se atoleiros e o campo de futebol serve ao uso de drogas. Desse modo, o sistema não oferece opções, nutrindo o lumpesinato com as bugigangas da alienação, o que corresponde a uma marca de oposição em relação aos bem-nascidos que ocupam postos de excelência. $\mathrm{O}$ que resta acaba por ser rateado injustamente, cabendo aos subalternos propugnarem em favor dos espaços de dignidade por meio da cultura e da arte.

Capão Pecado é assim um libelo contra o racismo, o que se confirma na truculência policial como retrato da ineficiência do Estado. A pobreza situa-se como sepultura em vida, uma vez que muitos jovens não têm pelo que optar senão pelo vício e pelo crime, em grande escala assassinados pela polícia ou na guerra pelos postos de poder no narcotráfico. Em vista desse estado de coisas, o Capão Redondo é também caracterizado por sua carga de maldição, surgida de onde os despachos de macumba eram colocados. Assim, os evangélicos concorrem como forma de reverter para o caminho da fé os desvios do lugar esquecido por Deus. Num universo sem regras, onde a garantia dos direitos individuais não existe e o crime pontifica, além da insuficiência nos serviços de saneamento e energia elétrica, e na ausência de espaços de lazer, os cultos religiosos são um meio de legitimação da cidadania. Além disso, a cultura lança mão do hip-hop como expressão da sobrevivência.

\section{O testemunho da prisão}

Ao escrever suas memórias de dentro do presídio, onde cumpriu pena por homicídio e diversos outros crimes, Luiz Alberto Mendes (2009) nos apresenta em Memórias de um sobrevivente muito mais que uma autobiografia no sentido tradicional. O que o autor oferece é um painel da cri- 
minalidade como uma extensão da violência que se legitimou no âmbito dos crimes comuns num reflexo do autoritarismo perpetrado pela ditadura. Assim, o menino irrequieto, submetido à violência do pai alcoólatra, põe em prática seu desejo transgressor a partir de pequenos furtos que crescem em proporção, atingindo a condição de prática para a qual não haveria retrocesso. A violência, portanto, permeia sua vida desde o início, despertando-lhe o desejo de superação a partir dos furtos que lhe propiciam a sensação de liberdade.

As fugas de casa, além das tentativas frustradas de seguir uma conduta pautada pela obediência à ordem do trabalho resultam no descumprimento da autoridade paterna bem como na insubmissão à realidade de um salário injusto e aviltante, incompatível com a demanda de desejos que emanava de sua condição de jovem ávido por usufruir o infinito das sensações. Arrimado à convivência com outros jovens evadidos de suas famílias, o álcool e as drogas passam à condição de estimulantes na prática dos furtos a pedestres e na invasão de domicílios, entre as modalidades dos crimes que comete, numa afirmação junto ao ambiente marginal.

Vale lembrar que o relato de Luiz Alberto Mendes coincide com o auge dos anos de rebeldia da juventude em todo o mundo. A citação à Jovem Guarda e aos Rolling Stones exemplifica o desejo de plena satisfação como sentimento que visava à superação de um mundo retrógrado, incompatível com a carga dos desejos que se evidenciam. Ser jovem significava insurgir-se contra uma ordem de valores que vigiam sob a tutela de um regime autoritário que despejava no país uma forte propaganda ideológica de cunho moralista e conservador. A rebeldia pontifica como ação cuja causa não correspondia a uma reação de cunho político, mas aos reflexos do regime que vitimou indistintamente criminosos de todos os tipos. Assim, seu período do ingresso no mundo do crime corresponde a uma mudança significativa na vida brasileira, coincidindo o surto de desenvolvimento econômico com o recrudescimento da truculência e do arbítrio, quando o apelo do consumo de bens num país de economia dependente instiga o desejo dos subalternos, sendo que da pobreza crônica resulta a explosão generalizada da criminalidade.

Não há como negar que a violência assume o papel de protagonista destacada da ficção brasileira urbana, a partir dos anos 60 do século $\mathrm{XX}$, principalmente durante a ditadura militar, traduzindo a introdução do país no círculo do capitalismo avançado. A industrialização crescente desses anos vai - em última instância - dar força à literatura centrada na vida das grandes cidades que incham e se deterioram; daí a ênfase em todos os problemas sociais e existenciais decorrentes, entre eles a ascensão da violência a níveis insuportáveis. Está forma- 
do o novo cenário para a revitalização do realismo e do naturalismo, agora com tintas mais sombrias, não mais divididos em "campo" e "cidade", como antes, mas ancorados numa única matéria bruta, fértil e muito real: a cidade cindida, ou seja, já irremediavelmente dividida em "centro" e "periferia"; em "favela" e "asfalto", em "cidade" e "subúrbio", em "bairro" e "orla", dependendo o uso desses termos da região do país (Pellegrini, 2008, p. 44).

Assim, configura-se um rosário de crimes e expiações que se inserem como via de mão única, na medida em que o jovem delinquente não vê opções. Entre a convivência com o pai alcoólatra e a reclusão a um reformatório, a liberdade das ruas preenche o anseio de um imediatismo que se projeta como possibilidade. No entanto, o tributo elevado a ser pago por cada situação incontornável indica um mundo de violência do qual o menor infrator não tem como se evadir. Recomeçar a vida, retornar à casa paterna, abandonar as ruas e deixar as drogas são condições que se conflitam no interior de quem se depara com a falta de perspectivas para o presente. Cabe-lhe, somente, a penalidade imposta pelo ambiente dos reformatórios onde a atividade criminosa se aperfeiçoa a partir de situações de estupro, tortura e espancamento.

Luiz Alberto Mendes narra sua trajetória criminosa até o momento em que, ao matar um guarda civil que reagiu ao assalto a um posto de gasolina, recebe da policia toda uma carga de tortura correspondente ao espírito de corpo da instituição como exercício sádico da vingança contra quem tirara a vida de um de seus membros. Os requintes da crueldade que pesam sobre os presos comuns são os mesmos exercidos contra os presos políticos, ainda que as instituições repressoras não sejam as mesmas. Decorre daí um calvário de torturas e violências de todos os tipos, que se confirmam nas décadas de reclusão a que foi submetido. O confinamento a uma cela forte, onde ficaria por cerca de um ano, deveu-se quase todo à morte de um presidiário que tentara usá-lo sexualmente. $\mathrm{O}$ ambiente carcerário propicia a prática da sevícia que vai dos interrogatórios sob tortura à submissão dos presos, que, por fraqueza e instinto de preservação, se entregam ao abuso sexual dos que detêm o poder dentro das celas:

A violência praticada nos "porões da sociedade" via de regra ocupa um local paradoxal: por um lado a instituição responsável pela violência quer esconder suas práticas que fogem ao contrato social que estabelece o monopólio estatal da violência; por outro lado estas mesmas instituições - e sobretudo o aparato da repressão no caso específico da ditadura militar brasileira, período em que se passa a história narrada por Mendes - procuram ostentar suas garras, visando à intimidação da população. Não podemos esquecer que na 
ditadura, calcada, como os regimes totalitários, na suspensão dos direitos básicos dos cidadãos e na paradoxal institucionalização do estado de exceção, esta ambiguidade e contradição da violência estatal fica ainda mais explícita (Seligmann-Silva, 2006, p. 52-3).

No entanto, a vida de Luiz Alberto Mendes parece adquirir outro sentido a partir do martírio da reclusão numa cela forte. Confinado a um cubículo, sem convivência, passa a conversar, através da tubulação da privada, com um preso da mesma galeria, que lhe narrava sucessivos romances. Daí o presidiário avesso à leitura entra em contato com as obras criadas por Victor Hugo, Balzac, Dostoiévski e tantos outros que, através dos esgotos, ajudavam a lhe suprimir o isolamento. $O$ passo seguinte consiste em devorar a pilha de livros que lhe enviara o interlocutor dos subterrâneos, aproveitando a saída do confinamento para ter acesso a tudo quanto pudesse representar acúmulo de cultura livresca, na busca pela superação do que representara sua vida até aquele momento. Os livros se constituíram na possibilidade dialógica com o universo da prisão, onde a cultura do crime inviabiliza as condições de convivência.

A experiência de ter passado parte da vida na prisão, submetido a castigos em celas minúsculas, sofrendo espancamentos e privações fazem de Luiz Alberto Mendes o depositário fiel dessas Memórias de um sobrevivente, na medida em que seus companheiros de infortúnio, quase todos, foram dizimados pela ação das forças de repressão. Em liberdade, na luta por superar a condição de ex-detento, vive do direito autoral de seus livros e de seu trabalho de colunista. Os ditames de um mercado sempre prestes a alterar as regras do jogo também impõem revezes aos escritores. Fora como dentro dos reformatórios e presídios, a sobrevivência cobra sérias exigências a quem só conheceu a violência e a crueldade.

\section{A guerra da cidade}

O desnível social entre as camadas altas e a pobreza acaba por estabelecer encontros em lugares inesperados e nas situações mais estranhas. O consumo de drogas pelas populações urbanas se constitui no lado da violência em que o assalto a mão armada concorre na obtenção de recursos para a manutenção do narcotráfico. A instituição do crime se constitui num intrincado sistema cujos tentáculos se ramificam numa vasta rede para qual também concorre o lenocínio, explícito na prática da prostituição e do rufianismo. Assim, Alessandro Buzo (2007) expõe em Guerreira, no plano de uma narrativa que não abre mão de sua matriz periférica, a condição dos que se situam num nível de exploração da marginalidade geradora do conflito de classes, na batalha travada por espaços de permanência. 
A personagem que protagoniza a ação narrativa envolve-se indistintamente com traficantes, assaltantes e empresários, passando da condição de presidiária à de empregada doméstica e depois à de proprietária de um bordel de luxo. A saga de Roseteminício com seu envolvimento nas drogas, a partir da relação com um assaltante. A ação criminosa de Tonho implica no sequestro de Wellington, que se sente atraído pela mulher do sequestrador. Com a chegada da polícia ao cativeiro e a fuga de Tonho para o Rio de Janeiro, Rose é presa, mas é justamente Wellington quem irá visitá-la e promoverá meios de colocá-la em liberdade, decorrendo daí, contra a vontade de sua família, que a rejeita, a união entre os dois. O reencontro com Tonho, que retornaria a São Paulo, ocorre quando Rose, após uma recaída, vai à Baixada do Glicério comprar drogas com uma colega de trabalho. Lá se depara com o antigo amante, por quem é violentada. Wellington decide então matar Tonho, mas no encontro ambos acabam morrendo.

Aí tem início uma nova rodada de vicissitudes num ir e vir da jovem bonita que aceita trabalhar como empregada doméstica, tornando-se amante do patrão e aos poucos lhe tomando dinheiro para consumir drogas. O desenrolar da narrativa aponta para a direção de um mundo onde todos são culpados por seus desvios, havendo apenas o dinheiro como possibilidade real de remissão do erro. Na verdade, de algum modo, em maior ou menor intensidade, todos se corrompem, seja o filho do patrão que se droga com a namorada, ou sua mulher que o trai com garotos de programa. A relação entre o ter e o não ter determina as normas que estabelecem a distinção abissal entre incluídos e excluídos. Os que estão do lado de fora são os batedores de carteira, traficantes de drogas, mulheres de programa. Do lado de dentro estão os empresários, industriais, prostitutas de luxo. Nesses espaços a personagem transita dando sentido ao título da obra, na medida em que seu infortúnio provisório se constitui numa saída com vistas à superação de sua condição. Da periferia para o apartamento de luxo, a vida aproxima tanto quanto distancia, na esfera do poder que o dinheiro confere, querendo manifestar um estágio de tempo em que o capitalismo redefine posições com extrema rapidez:

A fúria devoradora deste obsceno maquinismo tecnoburocrático autorreproduzido e incessantemente aperfeiçoado pelo desenvolvimento capitalista - encarna a mais insidiosa forma contemporânea de crueldade. Ao produzir o nexo de equivalências e vínculos entre homens e coisas, naturaliza a vontade de domínio como desejo do mais forte e dissemina a espoliação, em todas as versões mais sutis e sedutoras, como "modus operandi" da socialização.

Especificamente no Brasil, o espaço da presente reflexão, o totalitarismo nas sociedades de consumo soma, à violência já bem co- 
nhecida da manipulação das massas, o arsenal de violências gestadas por nossa globalização subordinada: a acentuada exclusão social, a financeirização econômica da vida coletiva, o depauperamento da soberania do Estado na regulação dos conflitos de interesses e, até mesmo, no combate à criminalidade organizada (Dias, 2004, p. 17).

O lugar da mulher guerreira que submerge no mundo da prostituição e das drogas corresponde à ocupação de um espaço que a protege provisoriamente da exposição à barbárie cotidiana, levando-a a ocupar um plano de inserção na classe dominante, quando tenta se regenerar do crime e do vício. No entanto esse trajeto não se confirma sem que sobre ele interfiram situações de obstáculo. Durante a reaproximação com Rodolfo, seu ex-patrão, conhece César, um malandro, viciado e assaltante, por meio de quem reincide nas drogas. Nisso fica explicitado que cada recaída no vício corresponde à dificuldade de aceitação de uma nova ordem de pertencimento para a qual a condição inerente à exclusão lhe serve de entrave. Para tanto atua com peso decisivo a influência por vezes devastadora que uma megalópole da dimensão de São Paulo pode exercer sobre as pessoas. O primado do consumo tem lugar de destaque, na medida em que não há outro caminho que conduza à superação da condição do subalterno senão almejar o que o mercado oferece. A obtenção desses bens, no entanto, contraria radicalmente a inserção na ordem do trabalho formal e assalariado, querendo sugerir que os meios ilegais acabam por legitimar uma determinada condição de acesso aos objetos de desejo.

O dinheiro do ex-amante agencia a abertura de um bordel para altos executivos onde Rose pontifica por sua beleza e seu poder de sedução sobre os homens. No entanto, esse espaço de ascensão não a liberta do vício das drogas, para o qual sua situação de crescente enriquecimento parece funcionar como um salvo-conduto. Os empresários endinheirados despejam seus instintos erógenos nas mulheres a peso de ouro pelo prazer que $o$ poder do dinheiro no mercado do amor lhes pode propiciar. O meretrício de alto luxo seria o veículo por meio do qual a cafetina e o empresário se reaproximariam. Rose e Rodolfo põem frente a frente suas queixas, mas terminam por buscarem o caminho do entendimento e da reconciliação. O dinheiro mais uma vez estipula suas regras ditando o ritmo de uma sequência de situações. Só ele pode redimir as humilhações transformando em cicatrizes as feridas abertas:

De um modo geral, a personagem da narrativa brasileira contemporânea "sabe o seu devido lugar". Na literatura, como nas telenovelas, na publicidade, no jornalismo, em suma, nas outras representações de nossa realidade (ainda que não necessariamen- 
te nela própria), a divisão de classes, raças e gênero é muito bem marcada: pobres e negros nas favelas e nos presídios, homens brancos de classe média e intelectuais nos espaços públicos, mulheres dentro de casa, negras na cozinha... Nas narrativas, os contatos entre diferentes estratos são, em geral, episódicos. Quando aparecem, quase sempre, estão marcados pela violência - mas aí, costuma-se privilegiar a violência aberta com que, por vezes, expressam-se integrantes das classes subalternas, em detrimento da violência silenciosa, estrutural, que é exercida sobre os dominados (Dalcastagnè, 2012, p. 49).

O destino ainda armaria outra cilada quando César reaparece para assaltar o casal agora reaproximado. A situação do marginal evidencia o conflito que se exemplifica ao reencontrar a prostituta viciada em drogas que agora almeja alcançar a condição de senhora casada, rompendo com uma espécie de determinismo social, inaceitável para os que não pertencem a esse meio, bem como para os que não conseguem superar sua própria situação. Mais ainda, a narrativa de Alessandro Buzo, ao evidenciar a luta insana dos seres no limite das coisas, aponta para um processo de desagregação e ao mesmo tempo de busca por inserção. Os meios justificam os fins na selva escura da cidade onde o reencontro com o destino pode ter resultados drásticos, mas pode também abrir novos acessos à situação de bem-estar no mundo. Assim, as contradições do sistema se reforçam, situando cada personagem numa zona limítrofe.

A busca por uma redenção que a vida na grande cidade tanto promete quanto insiste em negar só pode ser encontrada fora dos limites de onde recrudesce o crime e a violência. No assalto, César busca se vingar ao tentar violentar Rose diante de Rodolfo. Esta reage matando-o a tiros. $\mathrm{O}$ corpo sem vida estendido na calçada denuncia a decadência de um homem de aparência deprimente, sem documentos, a quem a polícia identifica como um viciado em drogas, logo pensando tratar-se de uma execução. $\mathrm{O}$ carro sequestrado foi atirado dentro de um rio na periferia da cidade por um policial que lhe fazia a segurança e o corpo do assaltante, enterrado na semi-indigência. Vítimas e algozes mudam de posição a cada momento em que a roleta da fortuna sugere mais um lance do jogo. Assim, o crime situa-se como um mal cujos sintomas podem reaparecer a qualquer momento, não havendo a possibilidade da recuperação completa, por mais que se queira sonhar com uma vida diferente. A crueldade e a violência são marcas indeléveis que se configuram no texto de Alessandro Buzo como expressões da contemporaneidade brasileira em sua feição mais cruel. 


\section{Referências}

BUZO, Alessandro (2007). Guerreira. 2. ed. São Paulo: Global.

DALCASTAGNÈ, Regina (2012). Literatura brasileira contemporânea: um território contestado. Vinhedo: Horizonte; Rio de Janeiro: EdUERJ.

DIAS, Ângela Maria (2004). Representações contemporâneas da crueldade: para pensar a cultura brasileira recente. In: DIAS, Ângela Mara; GLENADEL, Paula (Orgs.). Estéticas da crueldade. Rio de Janeiro: Atlântica.

(2005). As cenas da crueldade: ficção brasileira contemporânea e experiência urbana. Estudos de Literatura Brasileira Contemporânea, Brasília, n. 26, p. 87-96. FERRÉZ (2005). Capão Pecado. 2. ed. Rio de Janeiro: Objetiva.

JESUS, Carolina Maria de. (1960). Quarto de despejo. 2. ed. São Paulo: Francisco Alves. LINS, Paulo (2002). Cidade de Deus. 2. ed. São Paulo: Companhia das Letras.

MENDES, Luiz Alberto (2009). Memórias de um sobrevivente. 2. ed. São Paulo: Companhia das Letras.

SCHOLLHAMMER, Karl Erik (2009). Ficção brasileira contemporânea. Rio de Janeiro: Civilização Brasileira.

SCHWARZ, Roberto (1999). Seqüências brasileiras. São Paulo: Companhia das Letras.

Recebido em dezembro de 2012.

Aprovado em abril de 2013.

\section{resumo/abstract}

\section{Espaços da violência na narrativa brasileira contemporânea}

Valdemar Valente Junior

Este artigo enfatiza aspectos da violência como tema relevante na produção literária brasileira da última década. Os exemplos apresentados situam o discurso narrativo como referência do crescimento desordenado dos centros urbanos afetados por modelos econômicos geradores de injustiça e desigualdade. As comunidades pobres controladas pelo narcotráfico efetivam-se como cenário de ação a que se aliam o crime e a prostituição. As obras de Paulo Lins, Ferréz, Luiz Alberto Mendes e Alessandro Buzo aproximam o leitor da realidade social por eles já vivenciada.

Palavras-chave: crime, pobreza, drogas, violência, prostituição. 


\section{Spaces of the violence in the contemporary Brazilian narrative}

Valdemar Valente Junior

This article emphasizes aspects of the violence as a relevant theme in the literary Brazilian production of the last decade. The examples situate the discourse narrative as a consequence of the disordered growth of the urban centers affected by economic models that generate unfairness and social inequality. The needy communities controlled by the drug trafficking effective themselves as the stage where still dominates the crime and the prostitution. The works of Paulo Lins, Ferréz, Luiz Alberto Mendes e Alessandro Buzo approximate the reader to the social reality that was lived by them.

Keywords: crime, poverty, drugs, violence, prostitution. 